\title{
Correlation between physical fitness and fall efficacy in elderly women in Korea
}

\author{
Bog Ja Jeoung* \\ Department of Exercise Rehabilitation \& Welfare, College of Health Science, Gachon University, Incheon, Korea
}

The fear of falling is a common psychological consequence of falling, especially for elderly individuals. Fear of falling can lead to activity restriction and medical problems. The primary purpose of this study was to examine the correlation between fall efficacy and physical fitness factors in elderly women. We assessed physical fitness factors and investigated the Korean version of the Fall Efficacy Scale-International (KFES-I) in 173 participants. We investigated the correlation between physical fitness factors and fall efficacy. When the subjects were divid- ed into four groups according to physical fitness level, subjects with high 6-m walk, 30-s chair stand test, 30-s arm curl test, chair sit and reach test, 8-foot up and go test scores and high grip strength had low fall efficacy. Physical fitness factors were strongly associated with decreased fall fear, suggesting that physical fitness improvements play an important role in preventing or reducing the fear of falling.

Keywords: Elderly, Physical fitness, Fall efficacy

\section{INTRODUCTION}

Falls are a relatively common event in older adults. Approximately $30 \%$ of individuals over $65 \mathrm{yr}$ of age fall at least once a year (Tinetti, 2003). Falling is a major public health and medical problem that can cause serious injuries including fracture, brain injury, and even death. As aging progresses, muscle mass, muscle strength, and joint range decrease and strides narrow as walking speed declines. Stimulus response time and nerve conduction velocity decrease owing to changes in the nervous system, which leads to reduced balance ability. This decline in physical function reduces lower extremity strength, balance, and flexibility, thereby causing frequent falling during walking (Huh et al., 2010; Jeoung, 2014; Kressing et al., 2001).

In Korea, $21.4-41.6 \%$ of elderly patients receiving home care and $30.3 \%$ of elderly patients in nursing homes who have experienced falls (Gu et al., 2006), in who over 65 yr elderly, falling were higher prevalence than other elderly disease (Kim and Lee, 2006). Of community-dwelling elderly persons, $43 \%$ reported being fearful of falling, while $44 \%$ reported activity restrictions
(Robertson et al., 2002). Almost half of older adults transitioning to frailty had a fear of falling (Kressing et al., 2001). Fear of falling is not only the immediate result of falls but also a risk factor for falls which creates a vicious cycle between falls and fear of falling.

Various complex health problems arise in $50 \%$ of the elderly who have experienced falls; $10 \%$ of them require medical treatment and $5 \%$ experience fracture. Since $50 \%$ of the elderly individuals who are admitted to the hospital for fall-related injuries die within $1 \mathrm{yr}$, falling is a major cause of morbidity and mortality in the elderly (Tinetti and Powell., 1993). Since falling induces pain, restricts activities, and disables independent living, fear of falling and the restriction of social activities due to falling greatly reduce well-being and quality of life. As such, falling not only leads to physical damage in the elderly but can create serious problems for social well-being; therefore, studies on fall prevention and intervention are required. Recent research implicates fear of falling as a contributor to physical dependence among elderly persons (Tinetti and Powell., 1993), while other studies supported the close association among exercise, physical performance, and fear of falling (Li et al., 2005). The risk of falling can reportedly
${ }^{*}$ Corresponding author: Bog Ja Jeoung

Department of Exercise Rehabilitation \& Welfare, College of Health Science, 191 Hambakmoei-ro, Yeonsu-gu, Incheon 461-701, Korea

Tel: +82-32-820-4766; Fax: +82-32-820-4049, E-mail: bogja05@gachon.ac.kr Received: May 19, 2015 / Accepted: June 8, 2015
This is an Open Access article distributed under the terms of the Creative Commons Attribution Non-Commercial License (http://creativecommons.org/licenses/by-nc/3.0/) which permits unrestricted non-commercial use, distribution, and reproduction in any medium, provided the original work is properly cited. 
be reduced for those who exercise regularly, but few studies have examined its correlation with physical fitness. The purpose of this study was to examine the correlation between physical fitness and falling fears in the elderly.

\section{MATERIALS AND METHODS}

\section{Participants}

A total of 173 elderly women who were 65-85 yr old were recruited from a welfare center in Inchon city. All potential participants underwent a comprehensive explanation of the proposed study, its benefits and inherent risks, and the expected time commitment. Medical information (health status and medications) was obtained from participants using a questionnaire. The subjects were excluded if they were not able to walk without a cane or other assistive device or had known conditions and musculoskeletal problems limiting their safe participation in this study. The patients' general characteristics are shown in Table 1 .

\section{Physical performance}

The physical fitness test for seniors was developed by Roberta \& Jessie and included a 6-min walk test, grip strength, 30-sec arm curl test, 30-sec chair stand test, back scratch and chair sit and

\section{Table 1. Participant's demographics}

\begin{tabular}{lc}
\hline & $\mathrm{n}=173$ \\
\cline { 2 - 2 } Variable & $\mathrm{M} \pm \mathrm{SD}$ \\
\hline Age & $74.57 \pm 6.52$ \\
Weight (cm) & $152.62 \pm 5.29$ \\
Fall efficacy & $74.07 \pm 17.3$ \\
6-minute walk test (m) & $25.49 \pm 9.4$ \\
Grip-strength (kg) & $499.76 \pm 116.5$ \\
30-sec arm curl test (time) & $19.26 \pm 4.0$ \\
30-sec chair stand test (time) & $18.55 \pm 5.2$ \\
8 Foot Up-and Go (sec) & $6.34 \pm 9.7$ \\
Chair sit reach (cm) & $6.82 \pm 2.1$ \\
Unipedal stance (sec) & $8.8 \pm 8.82$ \\
BMl & $6.452 \pm 9.8$ \\
\hline
\end{tabular}

reach test, 8-foot up and go, unipedal stance, and body mass index.

\section{Fear of falling assessment}

This study approached fear of falling in two ways: (1) direct questioning focused on perceptive fear of falling; and (2) the Korean version of the Fall Efficacy Scale-International (KFES-I) to measure the confidence of avoiding falling during daily activities using the level of concern about falling. The direct questions asked whether participants had a fear of falling. The KFES-I has 16 items, each of which is scored from one to four for a total score of 16-64. According to the cut point suggested by Delbaere et al. (2004), we considered patients with a score $\geq 23$ as having a higher level of concern over falling.

\section{Statistical analysis}

Statistical analysis was performed using SPSS for Windows version 21 (IBM SPSS Inc., Chicago, IL, USA). A correlation analysis was conducted to examine the correlation between fall efficacy and physical fitness factors, and the correlated physical fitness factors were divided into quartiles to analyze the differences between groups. To investigate the differences in fall efficacy between physical fitness items, one-way analysis of variance (ANOVA) was performed.

\section{RESULTS}

There was a significant correlation between 6-min walk, 30-s chair stand test, 30-s arm curl test, chair sit and reach test, back scratch test, and 8-foot up and go test scores, unipedal stance, grip strength, and fall efficacy $(P<0.05)$ (Table 2$)$. The mean fall efficacy was 25.49 \pm 9.4 , higher than the fall efficacy risk score $(<23)$. Analysis of fall efficacy after the division of each physical fitness item into quartiles showed that fall efficacy was lower as physical fitness increased. Moreover, the group with the highest level of physical fitness (>75\%) had the lowest risk of fall efficacy compared to the group with the lowest level of physical fitness $(<25 \%)$. The group with high physical fitness ( $>75 \%)$ according to the 6-min walk, 30-s chair stand test, 30-s arm curl test, and 8 -foot up and go test scores and grip strength had lower fall effi-

Table 2. Correlation between fall efficacy and physical fitness

\begin{tabular}{lcccccc} 
Variable & 6-min walk & $\begin{array}{c}30 \text {-sec chair } \\
\text { stand test }\end{array}$ & $\begin{array}{c}30 \text {-sec arm } \\
\text { curl test }\end{array}$ & $\begin{array}{c}\text { Chair sit and } \\
\text { reach test }\end{array}$ & $\begin{array}{c}\text { Back scratch } \\
\text { test }\end{array}$ & $\begin{array}{c}\text { 8-Foot up and } \\
\text { go test }\end{array}$ \\
\hline Fall efficacy & $-0.594^{* *}$ & $-0.451^{* *}$ & $-0.264^{* *}$ & $-0.331^{* *}$ & $-0.162^{*}$ & $0.407^{* *}$ \\
\hline
\end{tabular}

${ }^{*} P<0.05$. ${ }^{* *} P<0.01$. 
Table 3. Difference of fall efficacy according to physical fitness level

\begin{tabular}{|c|c|c|c|c|c|}
\hline \multirow{2}{*}{ Variable } & \multicolumn{4}{|c|}{ Physical fitness level quartile } & \multirow{2}{*}{$P$} \\
\hline & $1-25 \%$ & $25-50 \%$ & $50-75 \%$ & $75-100 \%$ & \\
\hline \multirow[t]{2}{*}{6 min walk (m) } & $<430.25$ & $430.25-514$ & $514-574$ & $>574$ & \\
\hline & $n=43$ & $n=43$ & $n=43$ & $n=44$ & \\
\hline fall efficacy & $35.53 \pm 11.6$ & $27.50 \pm 7.2$ & $22.14 \pm 5.6$ & $19.55 \pm 3.4$ & $0.000 * * *$ \\
\hline \multirow[t]{2}{*}{ 30-sec chair stand test (number of time) } & $<12$ & 12-15 & 15-18 & $>18$ & \\
\hline & $n=37$ & $n=41$ & $n=53$ & $n=42$ & \\
\hline fall efficacy & $32.06 \pm 11.3$ & $27.55 \pm 9.2$ & $24.67 \pm 8.7$ & $20.74 \pm 5.8$ & $0.000^{* * *}$ \\
\hline \multirow[t]{2}{*}{ 30-sec arm curl test } & $<15$ & $15-19$ & 19-22 & $>20$ & \\
\hline & $n=39$ & $n=45$ & $\mathrm{n}=41$ & $n=48$ & \\
\hline fall efficacy & $29.95 \pm 10.2$ & $25.52 \pm 10.4$ & $26.4 \pm 9.3$ & $22.3 \pm 6.4$ & $0.000^{* * *}$ \\
\hline \multirow[t]{2}{*}{ Chair sit and reach test } & $<2.50$ & $2.5-8.5$ & $8.5-16$ & $>16$ & \\
\hline & $n=43$ & $n=42$ & $n=44$ & $n=44$ & \\
\hline fall efficacy & $29.9 \pm 10.8$ & $28.8 \pm 9.6$ & $22.11 \pm 6.8$ & $22.64 \pm 7.5$ & $0.000^{* * *}$ \\
\hline \multirow[t]{2}{*}{ Back scratch test } & $<-19.13$ & $-19.13--11$ & $-11-0$ & $>0$ & \\
\hline & $n=43$ & $n=45$ & $n=40$ & $n=45$ & \\
\hline fall efficacy & $29.07 \pm 11.5$ & $26.11 \pm 9.06$ & $24.67 \pm 9.2$ & $23.34 \pm 6.7$ & $0.035^{*}$ \\
\hline \multirow[t]{2}{*}{8 Foot up and go test } & $>7.36$ & $6.40-7.36$ & $5.58-6.40$ & $<5.58$ & \\
\hline & $n=42$ & $n=44$ & $n=43$ & $n=44$ & \\
\hline fall efficacy & $31.44 \pm 10.2$ & $26.8 \pm 10.8$ & $24.09 \pm 7.3$ & $20.26 \pm 3.8$ & $0.000^{* * *}$ \\
\hline \multirow[t]{2}{*}{ Grip strength } & $<16.88$ & 16.88-19.65 & $19.65-22.03$ & $>22.03$ & \\
\hline & $n=42$ & $n=45$ & $n=44$ & $\mathrm{n}=42$ & \\
\hline fall efficacy & $32.89 \pm 11.1$ & $24.79 \pm 7.06$ & $23.8 \pm 8.5$ & $22.9 \pm 8.1$ & $0.000^{* * *}$ \\
\hline \multirow[t]{2}{*}{ Unipedal stance } & $<2.27$ & 2.27-3.72 & $3.72-6.13$ & $>6.13$ & \\
\hline & $n=43$ & $n=43$ & $n=44$ & $n=43$ & \\
\hline fall efficacy & $27.05 \pm 8.87$ & $26.72 \pm 10.5$ & $24.33 \pm 7.5$ & $23.9 \pm 9.2$ & 0.263 \\
\hline
\end{tabular}

${ }^{*} P<0.05 .{ }^{* *} P<0.001$.

cacy points than the cut point suggested by Delbaere et al. (2004) (Table 3).

\section{DISCUSSION}

Risk of falling in the elderly includes not only the result of falling itself but also the high chance of injury accompanying falls. Analysis of the correlation between physical performance and fear of falling in this study showed that they have a strong correlation and that fear of falling decreases as physical fitness level increases. Studies have reported a strong correlation between muscle strength and balance with falling (Howland et al.,1993; Lawrence et al., 1998). Muscle strength is an important factor in standing posture and balance. That is, balance ability and falling are decided by how the body copes with a sudden postural disturbance in which an individual maintains a correlation between the instant reaction and the balance ability of the upper and lower body (Higuchi et al., 2004; Jeoung, 2014; Walker et al, 1991). For this reason, muscle strength declines and the incidence of falling becomes more frequent as aging progresses. The results of this study also verified that muscle strength, cardiovascular endurance, and agility are highly associated with a fear of falling as shown in previous studies. This finding suggests that improving physical fitness can prevent falling. Therefore, a regular exercise program that can enhance muscle strength, muscle endurance, cardiovascular endurance, and agility should be emphasized.

\section{CONFLICT OF INTEREST}

No potential conflict of interest relevant to this article was reported

\section{REFERENCES}

Delbaere K, Crombez G, Vanderstraeten G, Williams T, Cambier D. Fear-related avoidance of activity, falls and physical frailtu. A prospective community-based cohort study. Age Ageing 2004;33:368-373.

Gu MO, Jeon MY, Eun Y. The development \& effect of an tailored falls prevention exercise for older adults. J Korea Aca Nur 2006;36: 341-352. Higuchi H, Sudo H, Tanaka N, Fuchioka S, Hauashi Y. Does fear of fall- 
ing relate to low physical function in frail elderly person: association of fear of falling, balance and gait. J Jpn Phys Ther Assoc 2004;7:41-47.

Howland J, Perterson EW, Levin WC, Fried L, Pordon D, Bak S. Fear of falling among the community: occupational therapy interventions. J Aging Health 1993;5:229-243.

Huh JH, Lim S, Lee DH. Development of the Korean fall efficacy scale-international for the elderly. Korea J Phys Edu 2010;49:193-201.

Jeoung BJ. Relationship of exercise with frailty, depression, and cognitive function in older women. J Exerc Rehabil 2014;10(5):291-294.

Kim JM, Lee MS. Risk factors for falls in the elderly population in Korea: an analysis of the third Korea National Health and Nutrition Examination Survey data. Korean J Health Educ 2007;24:23-39.

Kressig RW, Wolf SL, Sattin RW. Association with demographic, functional and behavioral characteristics with activity-related fear of falling among older adults transitioning to frailty. J Am Geriatr Soc 2001;49:1456-1462.
Lawrence RH, Tennstedt SL, Kasten LE. Intensity and correlates of fear of falling and hurting oneself in the next year. J Aging Health 1998;10:267286.

Li F, Fisher KJ, Harmer P, McAuley E. Falls self-efficacy as a mediator of fear of falling in an exercise intervention for older adults. J Gerontol B Psychol Sci Soc Sci 2005;60(1):P34-40.

Robertson MC, Campbell AJ, Gardner MM. Preventing injuries in older people by preventing falls; a meta-analysis of individual-level data. J Am Geriatr Sco 2002;50:905-911.

Tinetti ME. Clinical practice. Preventing falls in elderly person. N Engl J Med 2003;348:42-49.

Tinetti ME, Powell L. Fear of falling and low self-efficacy; a cause of dependence in elderly person. J Gerontol 1993;48:35-38.

Walker JE, Howland J. Falls and fear of falling among elderly persons living in the community: occupational therapy interventions. Am J Occup Ther 1991;45:119-122. 